\title{
COVID-19 risk perception among Indonesians in early stage of the outbreak
}

\author{
Ratih Oktri Nanda ${ }^{1}$, Lolita Lolita ${ }^{2}$, Wiwik Indayati ${ }^{3}$, Ivong Rusdiyanti ${ }^{4}$, Nurjannah ${ }^{5}$, Azis Ikhsanudin ${ }^{6}$, \\ Silvia Mareti ${ }^{7}$ \\ ${ }^{1}$ Department of Social Medicine and Health Education, School of Public Health, Nanjing Medical University, P.R. China \\ ${ }^{2,6}$ Faculty of Pharmacy, Universitas Ahmad Dahlan, Special District of Yogyakarta Province, Indonesia \\ ${ }^{2}$ Research Division of Clinical Pharmacology, The First Affiliated Hospital of Nanjing Medical University, P.R.China \\ ${ }^{3}$ Department of Maternal and Adolescent Health, School of Public Health, Nanjing Medical University, P.R. China \\ ${ }^{4}$ Department of Basic and Community Nursing, School of Nursing, Nanjing Medical University, P.R. China \\ ${ }^{5}$ Department of Epidemiology, Faculty of Public Health, University of Indonesia, Indonesia \\ ${ }^{6}$ Department of Pharmaceutics, School of Pharmacy, China Pharmaceutical University, P.R. China \\ ${ }^{7}$ Academy of Nursing, Pangkal Pinang, Indonesia
}

\begin{tabular}{l}
\hline \hline Article Info \\
\hline Article history: \\
Received Oct 3, 2020 \\
Revised Jan 28, 2021 \\
Accepted Mar 11, 2021 \\
\hline
\end{tabular}

\section{Keywords:}

COVID-19

Emerging infectious disease

Indonesia

Risk perception

\begin{abstract}
Indonesia confirmed its first coronavirus disease 19 (COVID-19) case on 2nd March 2020, when other countries have already reported several numbers in the previous month. This study aimed to explore the risk perception of Indonesians in the early stage of the COVID-19 outbreak. This crosssectional study was conducted among 495 participants using a web-based questionnaire. Primary data were collected from 3rd to 27th March 2020 including the perceived severity, vulnerability, threat, self, and response efficacy of the participants. The results showed that the perceived threat of the outbreak in its early stage is the second highest compared to other diseases. The perceived severity among the participants was high. However, they had a low vulnerability. Those in the middle region showed a higher level of self and response efficacy. Meanwhile, people who work as private sector employee $(\beta=0.146, p=0.004)$, live in the western region $(\beta=-0.184$, $\mathrm{p}=0.000)$, with a higher knowledge score $(\beta=0.096, \mathrm{p}=0.032)$ had a higher perceived threat. These results found those who had high knowledge, was also had higher perceived risk. The most important of these studies have determined various factors related to risk perception, thus it could be good preliminary evidence for public health authorities to arrange an effective way for epidemic control.
\end{abstract}

This is an open access article under the CC BY-SA license.

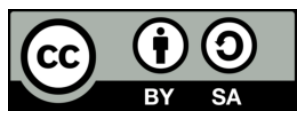

\section{Corresponding Author:}

Lolita Lolita

Faculty of Pharmacy

Universitas Ahmad Dahlan

Prof. Dr. Soepomo, Warungboto, Umbulharjo, Yogyakarta, Indonesia

Email: lolita@pharm.uad.ac.id; lolita_ur@yahoo.com

\section{INTRODUCTION}

In December 2019, a new infectious outbreak occurred in Wuhan, Hubei Province of China. This disease was found to be caused by a novel coronavirus and subsequently named severe acute respiratory syndrome 2 (SARS-CoV-2) [1]. This virus caused a disease called COVID-19, which is highly contagious and spreads by human-to-human transmission. It spreads rapidly to other countries outside of China and became a global pandemic. More than 30 million COVID-19 cases are registered worldwide until September $2020[2]$. 
The common symptoms found in the patients are fever, cough, fatigue, and shortness of breath. Older people and those with underlying conditions are more prone to severe outcomes such as acute respiratory distress syndrome (ARDS) [3]. Several proposed vaccines for this disease are currently being put into clinical trials. In the meantime, the public was implored to take self-precautions by practicing basic hygiene and self-quarantine [4].

In February 2020, COVID-19 had affected several countries, including those in South-east Asia. Meanwhile, the first case in Indonesia was reported on 2nd March 2020. This number increased significantly and reached more than 200,000 cases in September with almost 10,000 deaths [5]. As a country with a large population, with a lack of testing capacity and less strict social distancing measures, there is a tendency of a significant increase in the disease. Hence, understanding how people perceived their likelihood to get the disease, perceived the threat of the disease, and the response at the community and individual level in the early stage is vital as preliminary evidence of a better communication approach during an outbreak of emerging infectious diseases. This could be done by assessing the risk perception of the people.

One of the widely used theories to assess risk perception in health settings is the protection motivation theory (PMT). According to PMT, an individual has to perceive risk or threat before deciding to engage in protective behavior. PMT was used to assess the intention of an individual to engage in preventive behavior in several previous studies [6]-[8]. However, the main constructs in PMT (perceived vulnerability, perceived severity, and perceived threat) could be used to assess the risk perception. Several other studies used PMT in assessing risk perception in the healthcare setting [9]-[11]. In this study, we aimed to use PMT for assessing the risk perception of COVID-19, among general Indonesian populations. Additionally, we also aimed to explore COVID-19 related knowledge along with the precautionary actions taken to prevent COVID-19.

\section{RESEARCH METHOD}

This study was approved by the Ethics Committee of Aisyiyah University (No. 1305/KEPUNISA/IV/2020). Furthermore, informed consent and agreement to participate was obtained from each participant. Also, the confidentiality of the obtained data was maintained.

This was an analytic observational study using a cross-sectional design conducted from March 3rd to 27th 2020 among general Indonesian populations. Indonesians aged 17 years and above and currently living in Indonesia are eligible to participate in this study. A foreigner living in Indonesia and Indonesians living overseas are excluded. The survey was conducted using a link shared with online groups and social media. The sample size was determined by the assumption that the probability of the participant's knowledge of COVID-19 was 50\% [12]. Using a 95\% confidence interval, 5\% limit of precision, and 1.0 design effect, the sample size was 384 participants. At the end of the survey, the number of participants exceeded the maximum sample size. Accordingly, 495 responses were further analyzed.

Before distributing the questionnaire, a pilot study was conducted, and the data collected on 30 anonymous samples were first reviewed to determine the reliability of the questionnaire. The questionnaire was then modified accordingly. An online questionnaire through Google Form was used, which collected information on socio-demographic characteristics, knowledge, precautionary actions, perceived vulnerability, and severity, response as well as self-efficacy of COVID-19. Due to the unavailability of the risk perception questionnaire, this particular questionnaire was developed based on previous studies [13]. It was initially written in English and translated into Bahasa Indonesia.

\section{INSTRUMENTS AND DATA ANALYSIS}

The questionnaire collected socio-demographic information of participants such as age, sex, education, region, and occupation. Furthermore, their awareness about the pandemic, and whether they have lived or visited affected countries (China, South Korea, Japan, Iran, Italy) in the past six months were also included. Meanwhile, COVID-19 related knowledge was assessed with six items about the main symptoms and transmission of the disease. The total score of this knowledge ranged between 0-6. In addition, the precautionary actions taken by the participants were assessed by whether they had practiced at least one of twelve preventive measures of the disease.

The measurement of risk perception was made according to previous studies, based on the constructs of the protection motivation theory (PMT) [13]. The perceived severity assessed the severity of COVID-19 using a 10-point Likert scale, from 1 (not severe) to 10 (very severe). Meanwhile, the perceived vulnerability assessed the likelihood of acquiring this disease using a 5-point Likert scale, from 1 (very unlikely) to 5 (very likely). Furthermore, the perceived threat was used as the overall measure of risk perception, which used the square root of the multiplication of perceived severity divided by 2 and

Int. J. Public Health Sci., Vol. 10, No. 2, June 2021: 249 - 257 
vulnerability. The result was a perceived threat with a scale from 1 (low) to 5 (high). Also, the measure of risk perception was compared to other diseases and accidents such as SARS and MERS. The responseefficacy was assessed by asking how confident the participants think the people around them can take practical actions to prevent contracting COVID-19 using a 4-point Likert scale from 1 (not at all) to 4 (very much). Furthermore, self-efficacy was assessed by asking how confident they think they can prevent contracting the disease. The choices used a 4-point Likert scale, from 1 (not confident) to 4 (very confident).

A descriptive analysis was conducted on the socio-demographic characteristics and the study variables. The Kruskal-Wallis/Mann Whitney U test was used to explore the difference in the perceived threat among socio-demographic characteristics. We did the Kruskal-Wallis Test to see the difference in the perceived threat among the occupation variable. Furthermore, we conducted a Dunn-Bonferroni test for the post-hoc analysis. Also, multiple linear regression was conducted to determine the factors that are associated with perceived vulnerability, severity, and threat, each as a dependent variable. We divided the independent variables into two blocks, the first block consisting of all the sociodemographic variables and knowledge and awareness in the second block. The independent variables were included with socio-demographic variables in the first block, and COVID-19 related knowledge, as well as awareness in the second block. Furthermore, dummy variables were set for the categorical independent variables. All the results are significant when the p-value is $<0.05$. All of the statistical analyses were conducted with SPSS 22.0 (IBM Corp., Armonk, NY, USA).

\section{RESULTS AND DISCUSSION}

The majority of the participants were female (74.7\%), aged 17-25 (59.6\%), and living in the western region $(71.5 \%)$. Those with a bachelor's degree were $71.1 \%$, and students were $35 \%$. Overall, they were young individuals and students. Furthermore, $97.4 \%$ have heard of the disease, and only $4 \%$ reported living or visiting COVID-19 affected countries in the last six months. There was a difference in the perceived threat between sex, region, and occupation as shown in Table 1.

Table 1. Demographic characteristic of the participants

\begin{tabular}{|c|c|c|c|c|c|c|}
\hline \multirow{2}{*}{ No. } & \multirow{2}{*}{ Variables } & \multirow{2}{*}{$\mathrm{n}(\%)$} & \multicolumn{2}{|c|}{ Knowledge range (0-6) } & \multicolumn{2}{|c|}{ Perceived threat of COVID-19 } \\
\hline & & & Mean $\pm \mathrm{SD}$ & $\mathrm{p}$ & Mean $\pm \mathrm{SD}$ & $\mathrm{p}$ \\
\hline \multirow[t]{3}{*}{1.} & Sex* & & & & & \\
\hline & Male & $125(25.3)$ & $5.40 \pm 1.20$ & 0.289 & $3.15 \pm 1.01$ & 0.048 \\
\hline & Female & $370(74.7)$ & $5.57 \pm 0.79$ & & $2.94 \pm 1.03$ & \\
\hline \multirow[t]{6}{*}{2.} & Age (years) & & & & & \\
\hline & $17-25$ & $295(59.6)$ & $5.50 \pm 0.96$ & 0.676 & $2.99 \pm 1.05$ & 0.882 \\
\hline & $26-35$ & $112(22.6)$ & $5.58 \pm 0.74$ & & $3.04 \pm 1.02$ & \\
\hline & $36-45$ & $59(12)$ & $5.58 \pm 1.02$ & & $3.00 \pm 0.97$ & \\
\hline & $46-55$ & $19(3.8)$ & $5.63 \pm 0.68$ & & $2.93 \pm 0.85$ & \\
\hline & $>55$ & $10(2.0)$ & $5.30 \pm 1.05$ & & $2.83 \pm 1.28$ & \\
\hline \multirow[t]{3}{*}{3.} & Region* & & & & & \\
\hline & Western region & $354(71.5)$ & $5.58 \pm 0.82$ & 0.149 & $3.14 \pm 0.95$ & $0.000 *$ \\
\hline & Middle region & $141(28.5)$ & $5.40 \pm 1.11$ & & $2.64 \pm 1.13$ & \\
\hline \multirow[t]{5}{*}{4.} & Education & & & & & \\
\hline & Junior High School & $3(0.6)$ & $6.00 \pm 0.00$ & 0.189 & $2.82 \pm 0.74$ & 0.246 \\
\hline & Senior High School & $84(17.0)$ & $5.36 \pm 1.26$ & & $2.83 \pm 1.05$ & \\
\hline & Bachelor Degree & $352(71.1)$ & $5.53 \pm 0.86$ & & $3.05 \pm 1.03$ & \\
\hline & Postgraduate & $56(11.3)$ & $5.73 \pm 0.58$ & & $2.92 \pm 0.95$ & \\
\hline \multirow[t]{6}{*}{5.} & Occupation $* *$ & & & & & \\
\hline & Student & $173(35)$ & $5.37 \pm 1.07$ & $0.016^{*}$ & $2.79 \pm 1.08$ & $0.018 *$ \\
\hline & Private sector employee & $164(33.1)$ & $5.63 \pm 0.90$ & & $3.18 \pm 0.95$ & \\
\hline & Government worker & $52(10.5)$ & $5.58 \pm 0.69$ & & $3.01 \pm 0.98$ & \\
\hline & Entrepreneur & $22(4.4)$ & $5.59 \pm 0.59$ & & $3.32 \pm 1.09$ & \\
\hline & Others & $84(17.0)$ & $5.61 \pm 0.76$ & & $2.97 \pm 0.99$ & \\
\hline \multirow[t]{3}{*}{6.} & COVID-19 related awareness* & & & & & \\
\hline & Yes & $482(97.4)$ & $5.55 \pm 0.88$ & 0.072 & $3.01 \pm 1.02$ & $0.036^{*}$ \\
\hline & No & $13(2.6)$ & $4.43 \pm 2.22$ & & $2.12 \pm 1.03$ & \\
\hline \multirow[t]{3}{*}{7.} & $\begin{array}{l}\text { Previous visit to COVID-19 affected } \\
\text { countries in the last } 6 \text { months* }\end{array}$ & & & & & \\
\hline & Yes & $20(4)$ & $5.55 \pm 1.14$ & & $2.91 \pm 0.88$ & 0.790 \\
\hline & No & $475(96)$ & $5.53 \pm 0.91$ & 0.547 & $3.00 \pm 1.03$ & \\
\hline
\end{tabular}

* Significant $\mathrm{p}<0.05$ using Mann Whitney-U Tes

**Significant $\mathrm{p}<0.05$ using Kruskal Wallis test 
Among the participants, a higher knowledge was found in females with a mean score of 5.57, aged 46-55 (5.63), living in the western region (5.58), holding a postgraduate degree (5.73), and working in a private sector (5.63). Also, those who have heard of the disease had a higher knowledge with a mean score of 5.55. Furthermore, those who reported a previous visit to COVID-19 affected countries in the last six months had a slightly higher knowledge (5.55).

COVID-19 perceived vulnerability in this study was the third highest with a mean score of 2.44 (range 1-5). Meanwhile, that of the common cold was highest (2.91) and HIV/AIDS was the lowest (1.62). In terms of perceived severity, COVID-19 was seen as one of the most severe problems with a mean score of 8.12 (range 1-10). Other conditions with high severity were cancer (8.21), cardiovascular diseases (8.24), and HIV/AIDS (8.21). However, the common cold had the lowest perceived severity (7.06). After gathering the measurement, the perceived threat of COVID-19 during the outbreak was the second highest with a mean score of 2.99 (range 1-5), after traffic accident (3.05). However, Avian Influenza had the lowest perceived threat (1.99) compared to other diseases and accidents as shown in Table 2.

Table 2. Risk perception of COVID-19 and other diseases/accidents

\begin{tabular}{|c|c|c|c|}
\hline & $\begin{array}{c}\text { Perceived vulnerability (1-5) } \\
\text { Mean } \pm \text { SD }\end{array}$ & $\begin{array}{l}\text { Perceived severity (1-10) } \\
\text { Mean } \pm \text { SD }\end{array}$ & $\begin{array}{c}\text { Perceived threat (1-5) } \\
\text { Mean } \pm \text { SD } \\
\end{array}$ \\
\hline COVID-19 & $2.44 \pm 1.13$ & $8.12 \pm 2.77$ & $2.99 \pm 1.03$ \\
\hline SARS & $2.11 \pm 1.06$ & $7.99 \pm 2.84$ & $2.07 \pm 0.64$ \\
\hline MERS & $1.93 \pm 1.02$ & $7.91 \pm 2.91$ & $2.59 \pm 0.93$ \\
\hline Avian influenza & $2.01 \pm 1.06$ & $7.84 \pm 2.86$ & $1.99 \pm 0.63$ \\
\hline Tuberculosis & $2.13 \pm 1.15$ & $7.93 \pm 9.00$ & $2.73 \pm 1.01$ \\
\hline Common cold & $2.91 \pm 1.30$ & $7.06 \pm 2.83$ & $3.03 \pm 1.08$ \\
\hline Cancer & $2.06 \pm 1.07$ & $8.21 \pm 2.92$ & $2.73 \pm 0.98$ \\
\hline Cardiovascular disease & $2.15 \pm 1.08$ & $8.24 \pm 2.92$ & $2.75 \pm 0.98$ \\
\hline Traffic accident & $2.62 \pm 1.23$ & $7.93 \pm 2.84$ & $3.05 \pm 1.07$ \\
\hline Food poisoning & $2.41 \pm 1.16$ & $7.33 \pm 2.91$ & $2.81 \pm 1.06$ \\
\hline HIV/AIDS & $1.62 \pm 0.92$ & $8.21 \pm 3.03$ & $2.41 \pm 0.88$ \\
\hline
\end{tabular}

The total average of the precautionary actions taken by the participants was $83.3 \%$. Also, covering mouth when sneezing or coughing showed to be the most practiced precautionary actions (97\%). Furthermore, avoiding eating out in the food court or restaurant reported as the least practiced measure $(68.7 \%)$ as shown in Table 3.

Table 3. Precautionary actions taken to prevent COVID-19

\begin{tabular}{lc}
\hline \multicolumn{1}{c}{ Precautionary actions } & Correct answer percentage n (\%) \\
\hline Avoid contact with sick people & $444(89.7)$ \\
Avoiding close contact with another person when sick & $457(92.3)$ \\
Not going out when sick & $399(80.6)$ \\
Wearing a mask & $372(75.2)$ \\
Covering nose and mouth when sneezing or coughing & $480(97.0)$ \\
Washing hands with water and soap for at least 20 seconds & $449(90.7)$ \\
Using hand sanitizer when water is not available & $419(84.6)$ \\
Avoiding eating out in the food court or restaurant & $340(68.7)$ \\
Avoiding public gatherings or crowded place & $359(72.5)$ \\
Avoiding traveling to COVID-19 key-epidemic area & $479(96.8)$ \\
Avoiding traveling by plane or public transportation & $362(73.1)$ \\
Consuming health supplement to improve immunity & $392(79.2)$ \\
Total average of correct answers & $83.3 \%$ \\
\hline
\end{tabular}

The linear regression analysis found that region was significantly associated with perceived severity, vulnerability, and threat. Meanwhile, people who work as a private sector employee $(\beta=0.206, p=0.000)$, live in the western region $(\beta=-0.170, p=0.000)$, and had higher knowledge score $(\beta=0.89, p=0.047)$ had higher perceived severity. In terms of vulnerability, males $(\beta=-0.107, p=0.022)$, and those who live in the western region $(\beta=-0.091, \mathrm{p}=0.049)$ had a higher perceived vulnerability. Also, those who work as a private sector employee $(\beta=0.146, p=0.004)$, live in the western region $(\beta=-0.184, p=0.000)$, had higher knowledge score $(\beta=0.096, p=0.032)$ had higher perceived threat as shown in Table 4. 
Table 4. Linear regression analysis of COVID-19 perceived severity, vulnerability, and perceived threat

\begin{tabular}{|c|c|c|c|c|c|c|}
\hline \multirow{2}{*}{ Variables } & \multicolumn{2}{|c|}{ Perceived severity } & \multicolumn{2}{|c|}{ Perceived vulnerability } & \multicolumn{2}{|c|}{ Perceived threat } \\
\hline & $\beta$ & $\mathrm{p}$ & $\beta$ & $\mathrm{p}$ & $\beta$ & $\mathrm{p}$ \\
\hline Age & .752 & .415 & -.376 & .547 & .057 & .963 \\
\hline Sex (male is the reference) & -.026 & .568 & -.107 & .022 & -.091 & .043 \\
\hline \multicolumn{7}{|l|}{ Education } \\
\hline High School & .128 & .557 & .092 & .680 & .121 & .578 \\
\hline Bachelor & .219 & .399 & .141 & .597 & .203 & .431 \\
\hline Postgraduate degree $^{1}$ & .064 & .222 & .047 & .807 & .065 & .723 \\
\hline \multicolumn{7}{|l|}{ Occupation } \\
\hline Private sector employee & .206 & .000 & .041 & .433 & .146 & .004 \\
\hline Government worker & .656 & .512 & .003 & .947 & .036 & .465 \\
\hline Entrepreneur & .054 & .264 & .039 & .406 & .069 & .134 \\
\hline Others $^{2}$ & .076 & .164 & .001 & .990 & .041 & .401 \\
\hline Region (western region is the reference) & -.170 & .000 & -.091 & .049 & -.184 & .000 \\
\hline COVID-19 awareness (answer "no" is the reference) & .047 & .286 & .086 & .060 & .071 & .108 \\
\hline COVID-19 knowledge & .089 & .047 & .022 & .626 & .096 & .032 \\
\hline
\end{tabular}

1) Dummies for education. Reference category is junior high school

2) Dummies for occupation. Reference category is student

Age and knowledge were quantitative variable. The dependent variable models explained less than $10 \%$ of the variance, except the model with the perceived threat as the dependent variable. The first model (M1) only included socio-demographic factors, meanwhile, the second (M2) included COVID-19 awareness, and related knowledge, as well as socio-demographic factors. Model for the total population explained 10.1\% of the variance in terms of perceived threat when knowledge and awareness were included in M2. In terms of the vulnerability, M1 explained $4.1 \%$ of the total population, and M2 explained $4.9 \%$. M1 in perceived severity explained $8.8 \%$, and M2 explained $9.9 \%$ of the total variance as shown Table 5. Furthermore, the proportion of variance was higher when knowledge and awareness were included. No significance was found in the model with perceived vulnerability as the dependent variable. In terms of response and self-efficacy, participants in the middle region were very confident that people can take practical actions to prevent themselves from acquiring COVID-19. They also reported higher self-efficacy than in the western region as shown in Figure 1.

Table $5 . \mathrm{R}^{2}$ of the different steps in the linear regression model of the risk perception

\begin{tabular}{lcccccc}
\hline & \multicolumn{2}{c}{ Perceived severity } & \multicolumn{2}{c}{ Perceived vulnerability } & \multicolumn{2}{c}{ Perceived threat } \\
& $\mathrm{R}^{2}$ & $\mathrm{p}$ & $\mathrm{R}^{2}$ & $\mathrm{p}$ & $\mathrm{R}^{2}$ & $\mathrm{p}$ \\
\hline $\mathrm{R}^{2}$ step 1 & .088 & .000 & .041 & .089 & .086 & .000 \\
$\mathrm{R}^{2}$ step 2 (full model) & .099 & .000 & .049 & .058 & .101 & .000 \\
Adjusted $\mathrm{R}^{2}$ full model & .071 & & .019 & & .073 & \\
\hline $\mathrm{R}^{2}$ step 1 for the the sion
\end{tabular}

$\mathrm{R}^{2}$ step 1 for the the socio-demographic variables

$\mathrm{R}^{2}$ step 2 for the socio-demographic variables, knowledge and awareness

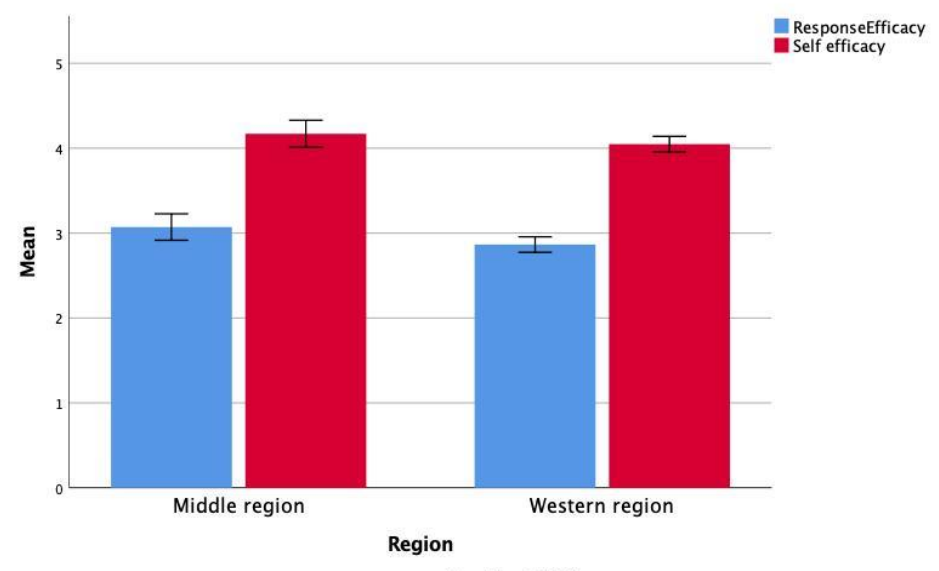

Figure 1. Response efficacy and self-efficacy based on region 


\subsection{Precautionary actions}

The total average of precautionary actions was $83.3 \%$. The main measures were covering mouth when sneezing or coughing (97\%), avoiding close contact with other people when sick (92.3\%), and avoiding traveling to high impacted areas $(96.8 \%)$. This finding is in line with a study in Hong Kong on the Avian Influenza outbreak, which reported that during the onset, $71 \%-81 \%$ of the participants avoided crowded places, going out, and traveling abroad [14].

Two weeks after the first confirmed cases, "Indonesian president pronounced some social distancing orders including closure of schools and workplaces" [15]. Around two weeks after the first two cases confirmed, the government created a Task Force (Gugus Tugas) for accelerating the handling of COVID-19 through a Presidential Decree (Keppres) 7/2020 [16]. Only on March $31^{\text {st }}, 2020$, the president pronounced the large-scale social distancing policy where the local government could limit the mobility of people and goods in and out of the area unless permission is acquired from the Health Ministry. Additionally, the policy mentioned that it includes closure of schools and workplaces, limitation of religious activities, and limitation of public activities [17]. However, these policies were not strictly imposed. Only 14 out of 34 provinces in Indonesia implemented this policy. At the end of the month, the president pronounced the COVID-19 outbreak as a national disaster.

At the early stage, public willingness to comply with the measures was important in controlling the outbreak [18]. The least practiced precautionary measures in this study are related to daily activities, such as gathering and eating in a restaurant. In a study of precautionary behavior during an infectious disease outbreak, the intention to practice safety measures was associated with the government's effectiveness [19], [20]. However, with no strict policy and hesitation in implementing lock-down in the early stage of the outbreak, the public activity outside is unavoidable.

\subsection{Risk perception: Protection motivation theory (PMT) constructs}

In this study, the perceived threat of COVID-19 is one of the highest along with road traffic accidents. Therefore, this suggested that the populations consider the disease as a potential health problem, and already perceived it as a threat. Severe acute respiratory syndrome (SARS), Avian Influenza, and other previous emerging infectious diseases were considered similar to COVID-19 in terms of risk perception as a serious health threat to people. Our study finding is in line with a study in Egypt, which demonstrated that in the early stage of the outbreak, the public perceived COVID-19 as a life-threatening danger [21]. Furthermore, a previous study in Vietnam showed that $75 \%$ of the participants considered Avian Influenza as a serious threat at the beginning of the outbreak [22]. Among the participants in a study in the UK, SARS was considered a perceived threat in the initial phase before the containment [23], [24].

Those previous studies have shown that in the early phase of the outbreak, the public was concerned about the disease and thought it could be a danger to their health. The dimension of psychological risk in the psychometric paradigm shows that dread (the feeling of dread and the perceived of a catastrophic potential of the hazard), as well as the risk of the unknown (where the hazard is judged to be unknown or new) shaped risk perception of people [25]. Other diseases mentioned in our study have been previously known-or even contained. However, although COVID-19 is caused by the same group of viruses, which is a novel coronavirus, the disease is still considered new that future exploration and research is still needed [26]. Therefore, in our study, we reported that compared to other diseases, COVID-19 is considered a public health threat due to the evolving research that still needed to be conducted at the beginning of the outbreak.

In this study, the region was associated with a perceived threat. Meanwhile, in previous research of SARS in a wider area, a similar finding was reported that a region was associated with perceived vulnerability, severity, and threat [24]. At the beginning of the outbreak, the number of cases in the western region is higher than in the middle region. Our study found that the perceived threat of participants in the western region towards COVID-19 is higher than participants in the middle region. This finding is in contrast with an earlier study that showed risk perception is lower in the area where the outbreak is prevalent [27]. Since this study accounted only for two local regions, the finding needs to be interpreted with caution. Furthermore, other factors that are associated with the perceived threat are being a private sector employee and higher COVID-19 related knowledge. This finding is similar to a recent study that showed that personal knowledge of the disease is significantly associated with risk perception [28].

Elaborating the PMT constructs, it was found that the participants perceived COVID-19 as a serious health problem along with cardiovascular disease and HIV. People who work as private-sector employees who live in the western region with higher knowledge had more perceived severity. However, even though it was considered a serious disease, they perceived themselves as less likely to acquire it, which was slightly lower compared to the perceived threat. A similar finding was observed in a study of previous outbreaks such as A/H7N9 and Avian Influenza, where the participants considered the disease as a serious risk, but perceived that their chance of getting infected is low [22], [29]. This might be influenced by the majority of 
participants who were not in the high-risk category, or having adequate protection to prevent the disease. Moreover, the majority of the participants in our study are young people, who are not a high-risk category for getting COVID-19.

Also, it was assumed that low perceived vulnerability in the early stage of the outbreak was because the participants had low intention to comply with the government, or the outbreak was anticipated. Meanwhile, a study during the early phase of an infectious disease pandemic in the Netherlands found that the strong intention to comply with government measures was associated with perceived vulnerability However, the lower vulnerability might be because people have anticipated the risk, and practiced the protective behavior before the outbreak occurred [30].

After an individual evaluates risk as a part of threat appraisal, they will go through a process to cope with it. In this case, response and self-efficacy play a role [31]. The perceived threat was higher in the western region while coping appraisal was found in the middle. Those living in the middle region are confident that they could take preventive actions during the outbreak. Jakarta as the capital and other parts of the western region were surging in terms of the cases at the beginning of the outbreak. In the beginning case of COVID-19 on $2^{\text {nd }}$ March 2020, western region contributed to a higher number of cases than the other regions in Indonesia. These studies found that self and response efficacy among people in the western region was lower than in the middle region. The majority of participants in the western region consisted of students and employees. These two groups of people were more affected in social activity directly by the pandemic. In case when the first cases of outbreaks surged, they might still need to go to the school and the office. There still no strict regulations yet for limiting their social activity in the beginning case. Furthermore, the Indonesian government just ruled out the instructions of physical distancing by the end of March [16]. A previous study also reported that in terms of pandemic policy response, Indonesia was one of the countries with the medium case yet having a proportional response towards the pandemic [32]. Therefore, this might lead to a reduced public trust that subsequently decreases the response and self-efficacy of the people in the western region, where the regulations took place earlier. In addition, every job cannot be executed from home or online, therefore people still go out to work, despite the social distancing measure.

China was able to implement strict policies at the beginning, however other countries such as the USA and UK waited for at least a month to apply the same measure [33]. This might be influenced by the nature of the disease, which is a major concern when the effects become visible [34]. In Indonesia, it took more than a month to implement large scales social status due to concern of interfering with the public daily and economic activities. The government must first disburse the stimulus to those affected by the large-scale social restrictions (PSBB) policy [35]-[37].

Based on PMT, people will take higher precautionary actions when all of the PMT constructs such as perceived vulnerability, perceived severity, and a coping appraisal are high. In a previous study, perceived severity as one of the PMT constructs was relatively low. Therefore, the focus is needed to manage the pandemic towards the perceived severity [38]. Our study found the lower construct in perceived vulnerability. Therefore, in terms of communicating preparedness strategies, improving the pandemic response, delivering effective communication, and encouraging more precautionary actions, thus the perceived vulnerability needs more attention. When the public realizes that COVID-19 is a risk that can affect anyone, despite the ages, they will take more precautionary action to avoid getting the disease.

\section{CONCLUSION}

The knowledge among the participants was satisfactory, and the perceived severity and threat of COVID-19 were high. However, they had low perceived vulnerability. Participants in the middle region showed higher self and response efficacy. Risk perception is known as a trigger for precautionary actions. By knowing and understanding how public perceived COVID-19 in the early stage of the outbreak, the result of our study can be a preliminary approach for the health sector, stakeholders, and the government to provide a better communication in order to encourage the people to take more precautionary actions during a disease outbreak. However, our study emphasized the risk perceptions. Future exploration is needed to see how the risk perception affects the precautionary actions, especially in the early stage of a pandemic setting.

\section{REFERENCES}

[1] Huang, C et al., "Clinical features of patients infected with 2019 novel coronavirus in Wuhan, China," The Lancet, vol. 395, no. 10223, pp. 497-506, 2020, doi: 10.1016/s0140-6736(20)30183-5.

[2] JHU, "CSSE Coronavirus COVID-19 Global Cases (dashboard)." [Online]. Available: https://gisanddata.maps.arcgis.com/apps/opsdashboard/index.html\#/bda7594740fd40299423467b48e9ecf6. 
[3] Wu, C et al., "Risk Factors Associated With Acute Respiratory Distress Syndrome and Death in Patients With Coronavirus Disease 2019 Pneumonia in Wuhan, China," JAMA Internal Medicine, vol. 180, no. 7, pp. 934-943, 2020, doi: 10.1001/jamainternmed.2020.0994.

[4] Thanh Le, T et al., "The COVID-19 vaccine development landscape," Nature Reviews Drug Discovery 2020, doi: 10.1038/d41573-020-00073-5.

[5] CDC., "Coronavirus (COVID-19)," [Online]. Available: https://www.cdc.gov/coronavirus/2019-ncov/index.html.

[6] Yan, Y et al., "Application of the protection motivation theory in predicting cigarette smoking among adolescents in China," Addictive Behaviors, vol. 39, no. 1, pp. 181-188, 2014, doi: 10.1016/j.addbeh.2013.09.027.

[7] Bai, Y et al., "Protection motivation theory in predicting intention to receive cervical cancer screening in rural Chinese women," Psychooncology, vol. 27, no. 2, pp. 442-449, 2018, doi: 10.1002/pon.4510.

[8] Amaral, R. A et al., "Intention to Drive After Drinking Among Medical Students: Contributions of the Protection Motivation Theory," Journal Addiction Medicine, vol. 11, no. 1, pp. 70-76, 2017, doi: 10.1097/adm.0000000000000276.

[9] Winneg, K. M et al., "Differences Between Florida and the Rest of the United States in Response to Local Transmission of the Zika Virus: Implications for Future Communication Campaigns," Risk Analysis, vol. 38, no. 12, pp. 2546-2560, Dec 2018, doi: 10.1111/risa.13010.

[10] Ruthig, J. C., "Health Risk Perceptions and Exercise in Older Adulthood: An Application of Protection Motivation Theory," Journal of Applied Gerontology, vol. 35, no. 9, pp. 939-59, 2016, doi: 10.1177/0733464814544214.

[11] Gu, C et al., "Chinese women's motivation to receive future screening: the role of social-demographic factors, knowledge and risk perception of cervical cancer," European Journal Oncology Nursing, vol. 17, no. 2, pp. 154-61, Apr 2013, doi: 10.1016/j.ejon.2012.04.005.

[12] Lemeshow S et al., "World Health Organization. Adequacy of sample size in health studies," Wiley, 1990, https://apps.who.int/ iris/handle/10665/41607.

[13] de Zwart, O et al., "Perceived threat, risk perception, and efficacy beliefs related to SARS and other (emerging) infectious diseases: results of an international survey," International Journal Behavioral Medicine, vol. 16, no. 1, pp. 30-40, 2009, doi: 10.1007/s12529-008-9008-2.

[14] Lau, J. T et al., "Perceptions related to human avian influenza and their associations with anticipated psychological and behavioral responses at the onset of outbreak in the Hong Kong Chinese general population," American Journal of Infection Control, vol. 35, no. 1, pp. 38-49, Feb 2007, doi: 10.1016/j.ajic.2006.07.010.

[15] "Jokowi calls for ' social distancing' to stem virus spread," The Jakarta Post, ed, 2020.

[16] Ivanka, N, "Large-scale Social Restrictions: What's Next?," The Indonesian Journal of International Clinical Legal Education, vol. 2, no. 2, pp. 201-214, 2020, doi: https://doi.org/10.15294/ijicle.v2i2.38324.

[17] PP No. 1 Tahun 2020, "State Financial Policy and Financial System Stability for Handling the Corona Virus Disease (COVID-19) Pandemic/Kebijakan Keuangan Negara dan Stabilitas Sistem Keuangan Untuk Penanganan Pandemi Corona Virus Disease (COVID-19)," 2020.

[18] Raude, J. and Setbon M., "Lay perceptions of the pandemic influenza threat," European Journal Epidemiology, vol. 24, no. 7, pp. 339-42, 2009, doi: 10.1007/s10654-009-9351-x.

[19] Sadique, M. Z et al., "Precautionary behavior in response to perceived threat of pandemic influenza," Emerging Infectious Diseases, vol. 13, no. 9, pp. 1307-13, Sep 2007, doi: 10.3201/eid1309.070372.

[20] Blendon, R. J et al., "Public response to community mitigation measures for pandemic influenza," Emerging Infectious Diseases, vol. 14, no. 5, pp. 778-86, 2008, doi: 10.3201/eid1405.071437.

[21] Abdelhafiz, A. S et al., "Knowledge, Perceptions, and Attitude of Egyptians Towards the Novel Coronavirus Disease (COVID-19)," Journal Community Health, pp. 1-10, Apr 21 2020, doi: 10.1007/s10900-020-00827-7.

[22] Figuié, M. and Fournier T, "Avian influenza in Vietnam: chicken-hearted consumers?," Risk Analysis, vol. 28, no. 2, pp. 441-51, Apr 2008, doi: 10.1111/j.1539-6924.2008.01039.x.

[23] Washer, P, "Representations of SARS in the British newspapers," Social Science \& Medic, vol. 59, no. 12, pp. 2561-71, 2004, doi: 10.1016/j.socscimed.2004.03.038.

[24] Smith, R. D, "Responding to global infectious disease outbreaks: lessons from SARS on the role of risk perception, communication and management," Social Science \& Medic, vol. 63, no. 12, pp. 3113-23, 2006, doi: 10.1016/j.socscimed.2006.08.004.

[25] Weber, E. U, "Risk: Empirical Studies on Decision and Choice," International Encyclopedia of the Social \& Behavioral Sciences, N. J. Smelser and P. B. Baltes Eds. Oxford: Pergamon, 2001, pp. 13347-13351.

[26] Yi, Y., Lagniton P. N. P., Ye S., Li E, and Xu R.-H., "COVID-19: what has been learned and to be learned about the novel coronavirus disease," International journal of biological sciences, vol. 16, no. 10, pp. 1753-1766, 2020, doi: 10.7150/ijbs.45134.

[27] Ji, L.-J., Zhang Z., Usborne E, and Guan Y, "Optimism across cultures: In response to the severe acute respiratory syndrome outbreak," Asian Journal of Social Psychology, vol. 7, no. 1, pp. 25-34, 2004, doi: 10.1111/j.1467839X.2004.00132.x.

[28] Dryhurst, S et al., "Risk perceptions of COVID-19 around the world," Journal of Risk Research, pp. 1-13, 2020, doi: 10.1080/13669877.2020.1758193.

[29] Cui, B., Liao Q., Lam W. W. T., Liu Z. P., and Fielding R., "Avian influenza A/H7N9 risk perception, information trust and adoption of protective behaviours among poultry farmers in Jiangsu Province, China," BMC Public Health, vol. 17, no. 1, p. 463, May 18 2017, doi: 10.1186/s12889-017-4364-y. 
[30] Brewer, N. T., Chapman G. B., Gibbons F. X., Gerrard M., McCaul K. D, and Weinstein N. D., "Meta-analysis of the relationship between risk perception and health behavior: the example of vaccination," Health Psychology, vol. 26, no. 2, pp. 136-45, Mar 2007, doi: 10.1037/0278-6133.26.2.136.

[31] Rogers, R., Cacioppo J., and Petty R., "Cognitive and physiological processes in fear appeals and attitude change: A revised theory of protection motivation," Social Psychophysiology: A Sourcebook, pp. 153-177, 1983.

[32] Dewi, A et al., "Global policy responses to the COVID-19 pandemic: proportionate adaptation and policy experimentation: a study of country policy response variation to the COVID-19 pandemic," Health Promotion Perspection, vol. 10, no. 4, pp. 359-365, 2020/11/7 2020, doi: 10.34172/hpp.2020.54.

[33] Motta Zanin, G., Gentile E., Parisi A., and Spasiano D., "A Preliminary Evaluation of the Public Risk Perception Related to the COVID-19 Health Emergency in Italy," International Journal Environmental Research Public Health, vol. 17, no. 9, pp. 3024, 2020, doi: 10.3390/ijerph17093024.

[34] Pescaroli, G. A., D., "A definition of cascading disasters and cascading effects: Going beyond the "topping dominos’ metapphor," Planet@Risk, vol. 2 no. 3, pp. 58-67, 2015.

[35] Ramadhani, M. W., "Lockdown Policy as a Corona Desease (COVID-19) Management Efforts Asked from The Environmental Aspect of Life Based on Law Act No. 32 of 2009 Concerning Protection and Management of Environment," Veteran Law Review, vol. 3, no. 1, pp. 22-36, 2020.

[36] Naryono, E., "Impact Of National Disaster Covid-19, Indonesia Towards Economic Recession," Center for Open Science, pp. 1-10, 2020.

[37] Muzakki, F., "The Global Political Economy Impact of COVID-19 and The Implication to Indonesia " Journal of Social Political Sciences, vol. 1, no. 2, pp. 76-92, 2020.

[38] Voeten, H. A et al., "Sources of information and health beliefs related to SARS and avian influenza among Chinese communities in the United Kingdom and The Netherlands, compared to the general population in these countries," International Journal Behavioral Medicine, vol. 16, no. 1, pp. 49-57, 2009, doi: 10.1007/s12529-008-9006-4. 